\title{
Relationship of age at menarche on anthropometric index and menstrual irregularity in late adolescent girls in Seoul
}

\author{
Seung Eun Lee, MD', \\ Joo Yun Yang, $\mathrm{MD}^{1}$, \\ Ji Hyun Lee, MD', \\ Han Wool Kim, MD', \\ Hae Soon Kim, MD, PhD', \\ Hye Jin Lee, MD, $\mathrm{PhD}^{2}$, \\ Ji Young Oh, MD, PhD', \\ Yeon Ah Sung, MD, $\mathrm{PhD}^{2}$ \\ Departments of ${ }^{1}$ Pediatrics and \\ ${ }^{2}$ Internal Medicine, Ewha Womans \\ University School of Medicine, \\ Seoul, Korea
}

Purpose: To examine the relationship between menarcheal age and anthropometric indices and menstrual irregularity in late adolescent girls in Seoul.

Methods: We surveyed 4,218 fertile adolescent girls between the ages of 16 and 18 years to determine their anthropometric indices and menarcheal age. Measurements were taken from June 2008 to October 2009 at seven girl's high schools in Seoul, Korea. Participants were offered self-report questionnaire as a survey tool that included questions on anthropometric indices (height, weight, waist circumference), menarcheal age, menstrual pattern, frequency of menstruation per year.

Results: The participants were categorized into three groups based on menarcheal age: early menarche group (younger than 2 standard deviations [SD]), mid menarche group (within \pm 2 SD), late menarche group (older than 2 SD). The mean age of early menarche group was $9.9 \pm 0.2$ years, mid menarche group $12.5 \pm 0.9$ years, late menarche group $15.1 \pm 0.3$ years $(P<0.001)$. Heights were recorded as $160.4 \pm 5.2 \mathrm{~cm}, 161.8 \pm 4.9$ $\mathrm{cm}, 162.3 \pm 4.7 \mathrm{~cm}$ in early, mid, and late menarche group, respectively $(P=0.001)$. Body mass index (BMI) and waist circumference significantly were lager in early menarche group than mid and late menarche ones $(P<0.001)$. The menarcheal age had a positive correlation with height and negative correlations with weight, BMI, waist circumference $(P<0.001)$. The prevalence of oligomenorrhea was more frequent in late menarche group than early and mid menarche group.

Conclusion: The menarcheal age have positive relationship with height and inverse relationship with BMI and waist circumference in late adolescent girls in Seoul. Late menarcheal girls are disposed to have menstrual irregularity compared to early menarcheal girls.

Keywords: Menarche, Body mass index, Body height, Oligomenorrhea
Received: 28 August, 2013

Revised: 27 September, 2013

Accepted: 29 September, 2013

Address for correspondence: Hae Soon Kim, MD, PhD

Department of Pediatrics,

Ewha Womans University

Mokdong Hospital, Ewha Womans

University School of Medicine, 1071

Anyangcheon-ro, Yangcheon-gu,

Seoul 158-710, Korea

Tel: +82-2-2650-5569

Fax: +82-2-2653-3718

E-mail: hyesk@ewha.ac.kr

\section{Introduction}

Menarche is an essential event of sexual maturation and a major indicator of female maturity ${ }^{1)}$. The mean menarcheal age is known to be affected by various parameters including body fat accumulation, nutrition, environmental conditions, socio-economic status, genetic cause, and exposure to endo-neurocrine disruptors ${ }^{1-4)}$.

The menarche age showed recently downward tendency worldwide, with a diminution of 2-3 months per decade in western countries and the United States ${ }^{1,5-8)}$. In Korea, menarcheal age declined from 17 to 15 years in the 1960s, to 14 years in the 1980s, and to 13 years in the $1990 s^{9)}$.

Early menarcheal age is known to be a critical impact for many health disorders ${ }^{10-13)}$. Girls who experienced early menarche tend to be more obese in adulthood life ${ }^{14)}$. It has been suggested that girls who undergo menarche early may have a longer period of a positive energy 
balance or many endo-neurocrine components affect the speed of sexual maturation and body fat accumulation ${ }^{14)}$. Thus, early menarcheal age causes precocious shutdown of the plates, and girls who undergo menarche early have a shorter final adult height compared to late menarche groups ${ }^{15)}$.

The mean menarche age was found to gradually decline, while the age at beginning of regular menstrual cycle increased steadily $^{16,17)}$. These tendency may be due to a change in diet consumption to thin figure and an increase in physical activities, psychological stress affecting menstrual cycles ${ }^{18)}$. The most often demonstrated menstrual disorders are poly-menorrhea, oligomenorrhea, and dys-menorrhea ${ }^{19)}$. These are more frequent among younger adolescents and reach to less frequent $3-5$ years after beginning of menarche ${ }^{20)}$.

There have been many studies on the impacts of height, weight, and body structure on the menarche age. However, there is argument for the roles of those components. In this study, we focused on height, weight, body mass index (BMI), menstrual patterns, and menarche age in a large number of late adolescent girls in order to elucidate the influence of menarcheal age on anthropometric indices and menstrual irregularity in late adolescents.

\section{Materials and methods}

\section{Subjects}

This study was performed from June 2008 to October 2009 at seven girl's high schools which approved the survey and including some female college students in Seoul, Korea. The inclusion criterion was adolescent girls who underwent menarche more than 2 years prior to the survey. A total of 4,218 females, aged 16-18 years old, were enrolled in the study and categorized into three groups according to their menarcheal age: early menarche group (younger than 2 standard deviations [SD] of the mean menarcheal age), mid menarche group (between 2 $\mathrm{SD}$ of the mean menarcheal age), and late menarche group (older than 2 SD of the mean menarcheal age).

\section{Methods}

The survey tool was a self-report questionnaire that included questions on anthropometric data (height, weight, and waist circumference), menarcheal age, menstrual irregularity, and frequency of menstruation per year. We calculated BMI using weight and height. The Institutional Review Board of the hospital approved this study, and informed consent was obtained from all parents and participants.

\section{Statistical analysis}

The data were analyzed using SPSS ver. 17.0 (SPSS Inc., Chicago, IL, USA), and $P<0.05$ was used to determine statistical significance. The differences among anthropometric indices according to menarche age groups were analyzed by analysis of variance. Multiple comparisons were performed using Tukey test. Correlation analyses were used to investigate associations between menarcheal age and anthropometric indices.

\section{Results}

The mean menarcheal age of early menarche group was $9.9 \pm 0.2$ years, mid menarche group $12.5 \pm 0.9$ years, and late menarche group $15.1 \pm 0.3$ years $(P=0.000)$. The mean height of early menarche group was $160.4 \pm 5.2 \mathrm{~cm}$, mid menarche group $161.8 \pm 4.9 \mathrm{~cm}$, and late menarche group $162.3 \pm 4.7 \mathrm{~cm}$ $(P=0.001)$. BMI was $21.2 \pm 2.7 \mathrm{~kg} / \mathrm{m}^{2}$ in early menarche group, $20.1 \pm 2.4 \mathrm{~kg} / \mathrm{m}^{2}$ in mid menarche group, and $19.2 \pm 2.4 \mathrm{~kg} / \mathrm{m}^{2}$ in late menarche group $(P=0.000)$. The waist circumference of early menarche group was $70.8 \pm 7.5 \mathrm{~cm}$, mid menarche group $68.2 \pm 5.7 \mathrm{~cm}$, and late menarche group $67.1 \pm 5.9 \mathrm{~cm}(P=0.000)$. There were significant differences between the three menarcheal groups in height, BMI, and waist circumference. BMI and waist circumference were significantly greater among early menarche group compared with mid and late menarche groups. Late menarche group was tallest among the three groups (Table 1).

The menarcheal age was correlated positively to height

Table 2. Correlations of age at menarche and anthropometric data

\begin{tabular}{lcc}
\hline Variable & $r$ & $P$-value \\
\hline Height $(\mathrm{cm})$ & 0.095 & $<0.001$ \\
Weight $(\mathrm{kg})$ & -0.146 & $<0.001$ \\
Body mass index $\left(\mathrm{kg} / \mathrm{m}^{2}\right)$ & -0.213 & $<0.001$ \\
Waist circumference $(\mathrm{cm})$ & -0.143 & $<0.001$ \\
\hline
\end{tabular}

Table 1. Anthropometric data in late adolescent girls according to menarcheal groups

\begin{tabular}{lcccc}
\hline Variable & Early menarche & Mid menarche & Late menarche & $P$-value \\
\hline Age at menarche $(\mathrm{yr})$ & $9.9 \pm 0.2$ & $12.5 \pm 0.9$ & $15.1 \pm 0.3$ & $0.000^{\mathrm{a})}$ \\
No. $(\%)$ & $147(3.5)$ & $3,802(90.1)$ & $269(6.4)$ & 0.351 \\
Age $(\mathrm{yr})$ & $17.1 \pm 0.6$ & $17.2 \pm 0.7$ & $17.3 \pm 0.7$ & $0.001^{\mathrm{a})}$ \\
Height $(\mathrm{cm})$ & $160.4 \pm 5.2$ & $161.8 \pm 4.9$ & $162.3 \pm 4.7$ & $0.000^{\mathrm{a})}$ \\
Weight $(\mathrm{kg})$ & $54.6 \pm 7.5$ & $52.5 \pm 7.0$ & $50.4 \pm 6.7$ & $0.000^{\mathrm{a})}$ \\
Body mass index $\left(\mathrm{kg} / \mathrm{m}^{2}\right)$ & $21.2 \pm 2.7$ & $20.1 \pm 2.4$ & $19.2 \pm 2.4$ & $0.000^{\mathrm{a})}$ \\
Waist circumference $(\mathrm{cm})$ & $70.8 \pm 7.5$ & $68.2 \pm 5.7$ & $67.1 \pm 5.9$ & \\
\hline
\end{tabular}

Values are presented as mean \pm standard deviation unless otherwise indicated.

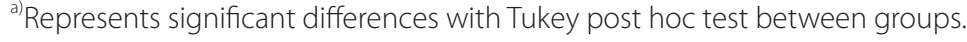



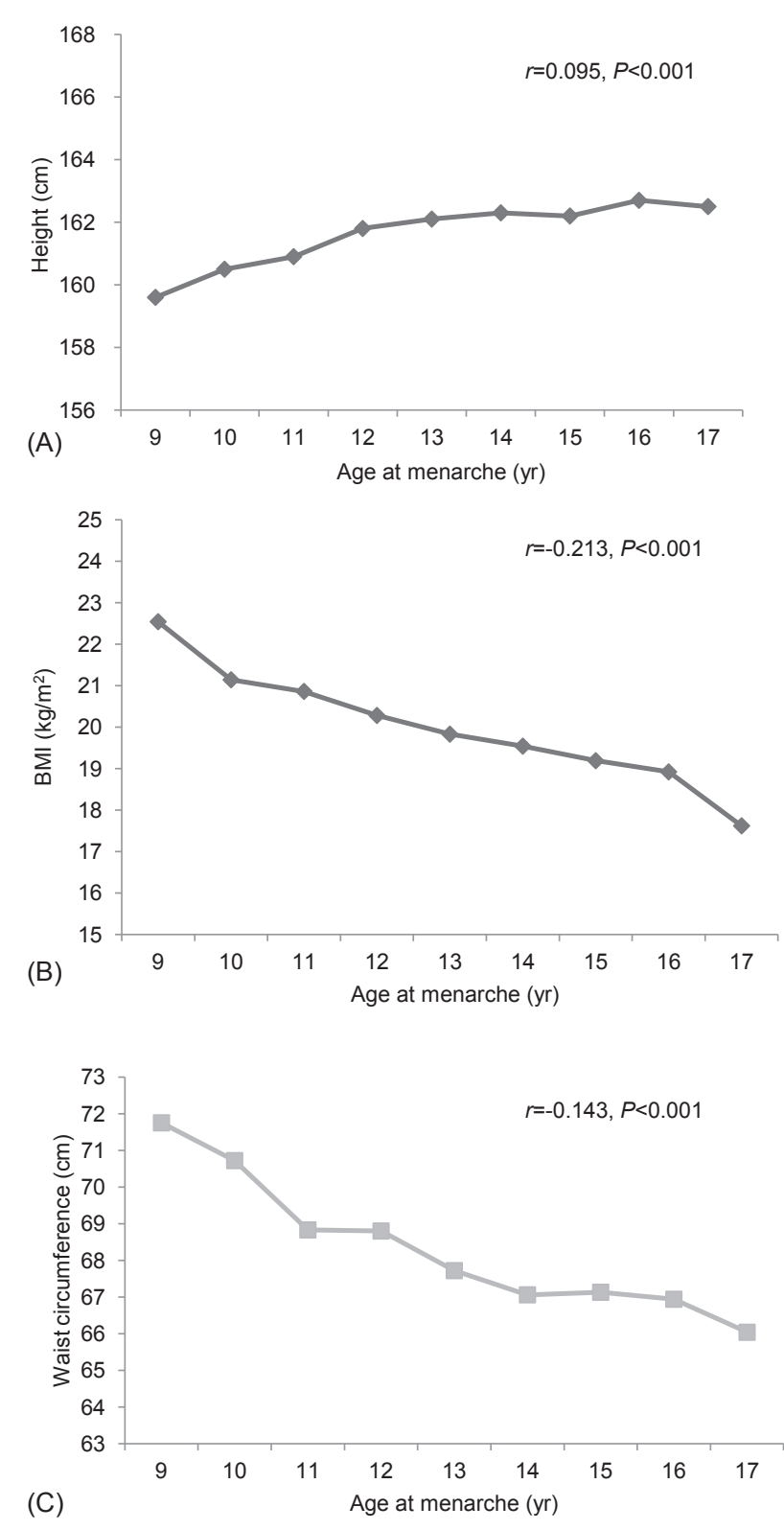

Fig. 1. Age at menarche and height (A), body mass index (BMI, B), and waist circumference $(C)$ of late adolescent girls.

$(r=0.095, P<0.001)$ and was correlated negatively to weight $(r=-0.146, P<0.001)$, BMI $(r=-0.213, P<0.001)$, and waist circumference $(r=-0.143, P<0.001)$ (Fig. 1, Table 2).

Regular menstruation patterns (more than nine times per year) was $86.7 \%$ in early menarche group, $78.9 \%$ in mid menarche group, and $63.4 \%$ in late menarche group. Oligomenorrhea (less than six times per year) was more common in late menarche group (Fig. 2).

\section{Discussion}

Menarche is a vital occurrence in a female life. The downward tendency of menarcheal age has been reported in many

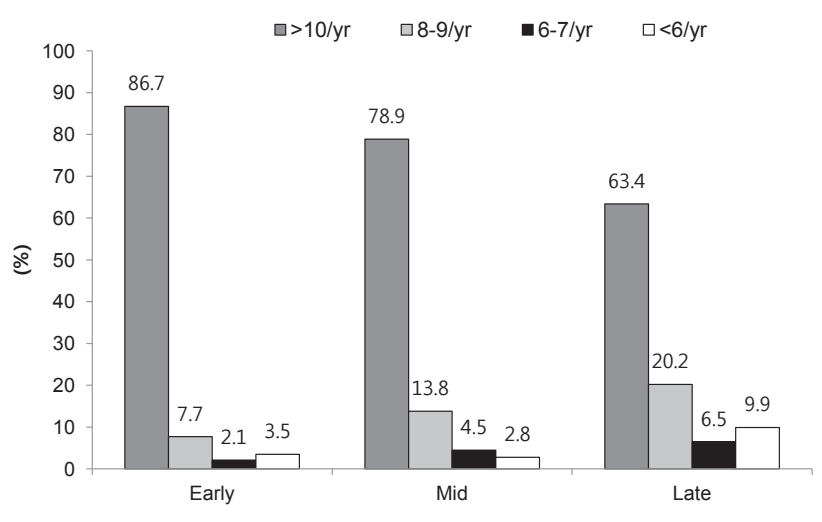

Fig. 2. Yearly frequency of menstruation in late adolescent girls according to menarcheal group.

countries $^{5,6,21-23)}$, containing Korea. Women born in 1920's had a mean menarcheal age of 17 years, while the mean menarcheal age of women born in 1980's was 14 years $^{7}$. We also found that the mean menarcheal age was $12.6 \pm 1.2$ years, confirming the recently decline tendency in Korean aldolescents. However, our participants were limited in the Seoul and not replace the whole Korean female adolescents.

The menarcheal age is influenced by many factors, such as nutrition, emotional stress, geographic and climatic condition, disease and genetic, socio-economic state ${ }^{1-4)}$. The impacts of anthropometric parameters, such as obesity indices and body fat, have previously been reported, but results were controversial $^{7,14,24-27)}$.

Numerous studies have proved a direct association between early menarcheal age and body weight, $\mathrm{BMI}^{7,14,24-27)}$. Although the mechanisms including to the inverse association between obesity and menarcheal age are not completely discovered, it has been reported that the speed of sexual maturation and body fat mass can affect this relationship ${ }^{14}$. Frisch and Revelle ${ }^{24)}$ found that the part of body fat acts as a endo-neurocrine stimulants in menarche event. In contrast, Garcia Cuartero et al. ${ }^{28)}$ found no correlation between menarcheal age and BMI, and Demerath et al. ${ }^{29)}$ showed that the menarcheal age was not reliant on BMI.

Girls who experience menarche early are likely to be more heavier in adulthood life ${ }^{14,30,31}$. These studies showed that late adolescent girls who underwent an early menarche had a lager BMI and waist circumference than mid and late menarche groups. We demonstrated an inverse association between menarcheal age and BMI and waist circumference in late adolescent girls. These results suggest that early sexual maturation triggers body fat mass accumulation. The upward tendency of adult obesity prevalence among early menarche group may largely represent the continuation of child obesity until adulthood later ${ }^{31}$. The inverse association of menarcheal age with BMI and obesity in middle aged women is not explained entirely by early childhood BMI. Instead, menarcheal age is probably a surrogation indicator for the speed of sexual maturation, which leads to different fat accumulation in the peripubertal period, and this continues into adulthood life ${ }^{30)}$. 
Although the fine endo-biological processes of the inverse association between menarcheal age and adulthood obesity prevalence are uncertain, it has been suggested that girls who undergo menarche early may have a longer period of a positive energy balance or that many endo-neurocrine stimulants influence the speed of sexual maturation and the obesity ${ }^{14)}$.

Global increasing tendency have been demonstrated for adult height as well as downward tendency for menarcheal age since the 1900 's. The taller height tendency is likely caused by alterations to nutrition, health status ${ }^{15)}$. Several studies have shown that women who undergo menarche earlier have a shorter final adult height compared with women who experience menarche later ${ }^{15,32}$. A study of 286,205 European women found that latest birth group has a earlier menarcheal age and a taller height, presenting that women who undergo menarche later will finally grow taller than women who undergo menarche earlier ${ }^{15}$. This positive association between menarcheal age and final adult height may be accounted by the earlier shutdown of plates due to the female estrogen hormone increment. Therefore, the menarcheal age perhaps has major roles on long bone growth ${ }^{15,32)}$. The height of menstruated girls is considerably taller than nonmenstruated girls ${ }^{33)}$, but an earlier shutdown of the plates may lead to a shorter final height at adulthood ${ }^{15,32)}$. In our study, the menarcheal age was correlated positively to height in late adolescent girls who had reached to their final adult height; the mean age of these subjects was 17.3 years and their height was likely to that of the final adult height.

Immediately after beginning of menarche, there is a temporary period with anovulatory cycles previous to ovulatory cycles. Few data are valid on the beginning age of regular menstrual cycle. Several studies have shown an upward tendency of anovulatory cycles with increasing menarcheal age $^{16,17,34-36)}$. Apter ${ }^{35)}$ found that these tendency was influenced by the menarcheal age, that is, earlier menarche girls who experienced menarche before 12 years have a more rapid onset of ovulatory menstrual cycles than girls having later menarche. Similarly, Hosokawa et al. ${ }^{17)}$ found that Japanese women who underwent menarche later were delayed regular menstrual cycle. The proportion of women who experienced the onset of regular menstrual cycles at 5 years and more after menarche was $26 \%, 30 \%, 37 \%$ for early (age at menarche $<10$ years), mid (age at menarche 11-14 years), late (age at menarche $>15$ years) menarche group, respectively $(P<0.0001)$. In a United States study, the interval period from menarche to the foundation of regular menstrual cycle was reported slightly positive association with menarcheal age ${ }^{36)}$. Our results also showed that oligomenorrhea was more common in late menarche group.

There are many hypotheses for oligomenorrhea in adolescence. A premature hypothalamus-pituitary-ovary axis may tend to oligomenorrhea and an anovulatory menstrual cycle ${ }^{17,19)}$. Anovulatory cycles are often found in the moment immediately after beginning of menarche, with menstrual cycles being irregular before enhancing of a positive feedback in the central nervous system result in the starting of regular menstrual cycle $^{17)}$. Irregular menstrual cycles have a crucial role on various female health conditions including psycho-social problem, infertility, and cardiovascular disorders in advanced age ${ }^{37)}$. In French women study, the age at beginning of regular menstrual cycle increased gradually and presented a profound increase in the period between menarcheal age and at beginning of regular menstrual cycle ${ }^{16)}$. Further studies are needed to identify the endo-neurocrine components connected to early menarche and the age at beginning of regular menstrual cycles.

Our study had some limitations. First, we used a cross sectional study design so that causality could not be determined. Second, the menarcheal age and anthropometric indices were gathered through self-reported questionnaires. Anthropometric indices were not directly measured through objective devices. The accuracy of recall of the data reliance on many factors, including of the interval term of recall, which has been reported to be a credible and logical tools for estimating age at menarche ${ }^{38)}$. In our study, the mean interval term of recall was 4.6 years (time of interview age, $17.2 \pm 0.7$ years; mean menarche age, $12.6 \pm 1.2$ years). Consequently, we assumed that recall bias would be low due to the short interval term of recall. Third we did not collect data that are known to be associated with menarcheal age, including physical activity, diet consumption, socio-economic and nutritional status.

A strong point of this study was our large participants number $(n=4,218)$ of late adolescent girls; this is the largest study investigating the influence of menarcheal age on anthropometric indices and menstrual irregularity in Korea.

In conclusion, we found a significant inverse relationship between menarcheal age and obesity and a positive relationship between menarcheal age and height. Girls who experience menarche later had a higher risk for menstrual irregularity in late adolescent girls in Korea. Further long term cohort investigations are needed to fully explain these causal relationships.

\section{Conflict of interest}

No potential conflict of interest relevant to this article was reported.

\section{Acknowledgments}

The work was supported by the Ewha Global Top 5 Grant 2013 of Ewha Womans University.

\section{References}

1. Parent AS, Teilmann G, Juul A, Skakkebaek NE, Toppari J, Bourguignon JP. The timing of normal puberty and the age limits of sexual precocity: variations around the world, secular trends, and changes after migration. Endocr Rev 2003;24:668-93.

2. Khan AD, Schroeder DG, Martorell R, Haas JD, Rivera J. Early childhood determinants of age at menarche in rural 
Guatemala. Am J Hum Biol 1996;8:717-23.

3. Kaplowitz PB, Slora EJ, Wasserman RC, Pedlow SE, Herman-Giddens ME. Earlier onset of puberty in girls: relation to increased body mass index and race. Pediatrics 2001;108:347-53.

4. Chowdhury S, Shahabuddin AK, Seal AJ, Talukder KK, Hassan Q, Begum RA, et al. Nutritional status and age at menarche in a rural area of Bangladesh. Ann Hum Biol 2000;27:249-56.

5. Herman-Giddens ME. Recent data on pubertal milestones in United States children: the secular trend toward earlier development. Int J Androl 2006;29:241-6.

6. de Muinich Keizer SM, Mul D. Trends in pubertal development in Europe. Hum Reprod Update 2001;7:28791.

7. Cho GJ, Park HT, Shin JH, Hur JY, Kim YT, Kim SH, et al. Age at menarche in a Korean population: secular trends and influencing factors. Eur J Pediatr 2010;169:89-94.

8. Lee JC, Yu BK, Byeon JH, Lee KH, Min JH, Park SH. A study on the menstruation of Korean adolescent girls in Seoul. Korean J Pediatr 2011;54:201-6.

9. Hong $\mathrm{CH}$, Rho HO, Song $\mathrm{SH}$. The sexual maturity rating of adolescent boys and girls in Korea. J Korean Pediatr Soc 1994;37:193-8.

10. Stockl D, Meisinger C, Peters A, Thorand B, Huth C, Heier $\mathrm{M}$, et al. Age at menarche and its association with the metabolic syndrome and its components: results from the KORA F4 study. PLoS One 2011;6:e26076.

11. Petridou E, Syrigou E, Toupadaki N, Zavitsanos X, Willett W, Trichopoulos D. Determinants of age at menarche as early life predictors of breast cancer risk. Int J Cancer 1996;68:193-8.

12. Jacobsen BK, Heuch I, Kvale G. Association of low age at menarche with increased all-cause mortality: a 37-year follow-up of 61,319 Norwegian women. Am J Epidemiol 2007;166:1431-7.

13. Lakshman R, Forouhi NG, Sharp SJ, Luben R, Bingham SA, Khaw KT, et al. Early age at menarche associated with cardiovascular disease and mortality. J Clin Endocrinol Metab 2009;94:4953-60.

14. van Lenthe FJ, Kemper CG, van Mechelen W. Rapid maturation in adolescence results in greater obesity in adulthood: the Amsterdam Growth and Health Study. Am J Clin Nutr 1996;64:18-24.

15. Onland-Moret NC, Peeters PH, van Gils CH, ClavelChapelon F, Key T, Tjonneland A, et al. Age at menarche in relation to adult height: the EPIC study. Am J Epidemiol 2005;162:623-32.

16. Clavel-Chapelon F; E3N-EPIC group. European Prospective Investigation into Cancer. Evolution of age at menarche and at onset of regular cycling in a large cohort of French women. Hum Reprod 2002;17:228-32.

17. Hosokawa M, Imazeki S, Mizunuma H, Kubota T, Hayashi K. Secular trends in age at menarche and time to establish regular menstrual cycling in Japanese women born between
1930 and 1985. BMC Womens Health 2012;12:19.

18. Gindoff PR. Menstrual function and its relationship to stress, exercise, and body weight. Bull N Y Acad Med 1989;65:774-86.

19. Flug D, Largo RH, Prader A. Menstrual patterns in adolescent Swiss girls: a longitudinal study. Ann Hum Biol 1984;11:495-508.

20. Apter D, Viinikka L, Vihko R. Hormonal pattern of adolescent menstrual cycles. J Clin Endocrinol Metab 1978;47:944-54.

21. Nakamura I, Shimura M, Nonaka K, Miura T. Changes of recollected menarcheal age and month among women in Tokyo over a period of 90 years. Ann Hum Biol 1986;13:547-54.

22. Chodick G, Huerta M, Balicer RD, Davidovitch N, Grotto I. Secular trends in age at menarche, smoking, and oral contraceptive use among Israeli girls. Prev Chronic Dis 2005;2:A12.

23. Jones LL, Griffiths PL, Norris SA, Pettifor JM, Cameron N. Age at menarche and the evidence for a positive secular trend in urban South Africa. Am J Hum Biol 2009;21:1302.

24. Frisch RE, Revelle R. Height and weight at menarche and a hypothesis of critical body weights and adolescent events. Science 1970;169:397-9.

25. Al-Awadhi N, Al-Kandari N, Al-Hasan T, Almurjan D, Ali S, Al-Taiar A. Age at menarche and its relationship to body mass index among adolescent girls in Kuwait. BMC Public Health 2013;13:29.

26. Farahmand M, Tehrani FR, Azizi F. Whether age of menarche is influenced by body mass index and lipoproteins profile? a retrospective study. Iran J Reprod Med 2012;10:337-42.

27. Oh CM, Oh IH, Choi KS, Choe BK, Yoon TY, Choi JM. Relationship between body mass index and early menarche of adolescent girls in Seoul. J Prev Med Public Health 2012;45:227-34.

28. Garcia Cuartero B, Gonzalez Vergaz A, Frias Garcia E, Arana Canete C, Diaz Martinez E, Tolmo MD. Assessment of the secular trend in puberty in boys and girls. An Pediatr (Barc) 2010;73:320-6

29. Demerath EW, Towne B, Chumlea WC, Sun SS, Czerwinski SA, Remsberg KE, et al. Recent decline in age at menarche: the Fels Longitudinal Study. Am J Hum Biol 2004;16:453-7.

30. Pierce MB, Leon DA. Age at menarche and adult BMI in the Aberdeen children of the 1950s cohort study. Am J Clin Nutr 2005;82:733-9.

31. Freedman DS, Khan LK, Serdula MK, Dietz WH, Srinivasan SR, Berenson GS, et al. The relation of menarcheal age to obesity in childhood and adulthood: the Bogalusa heart study. BMC Pediatr 2003;3:3.

32. Georgiadis E, Mantzoros CS, Evagelopoulou C, Spentzos D. Adult height and menarcheal age of young women in Greece. Ann Hum Biol 1997;24:55-9.

33. Goon DT, Toriola AL, Uever J, Wuam S, Toriola OM. 
Growth status and menarcheal age among adolescent school girls in Wannune, Benue State, Nigeria. BMC Pediatr 2010 19;10:60.

34. MacMahon B, Trichopoulos D, Brown J, Andersen AP, Aoki $\mathrm{K}$, Cole $\mathrm{P}$, et al. Age at menarche, probability of ovulation and breast cancer risk. Int J Cancer 1982;29:13-6.

35. Apter D. Hormonal events during female puberty in relation to breast cancer risk. Eur J Cancer Prev 1996;5:47682.

36. Garland M, Hunter DJ, Colditz GA, Manson JE, Stampfer MJ, Spiegelman D, et al. Menstrual cycle characteristics and history of ovulatory infertility in relation to breast cancer risk in a large cohort of US women. Am J Epidemiol 1998; 147:636-43.

37. Rowland AS, Baird DD, Long S, Wegienka G, Harlow SD, Alavanja $\mathrm{M}$, et al. Influence of medical conditions and lifestyle factors on the menstrual cycle. Epidemiology 2002;13:668-74.

38. Koprowski C, Coates RJ, Bernstein L. Ability of young women to recall past body size and age at menarche. Obes Res 2001;9:478-85. 